\title{
Validation of a method for ionospheric electron density reconstruction by means of vertical incidence data during quiet and storm periods
}

\author{
Gloria Miró Amarante, Sandro M. Radicella, Bruno Nava and Pierdavide Coïsson \\ The Abdus Salam International Centre for Theoretical Physics (ICTP), Trieste (Italy)
}

\begin{abstract}
A preliminary validation of the technique developed using the NeQuick ionospheric model and the «effective ionization parameter» $A z$, based on vertical total electron content data ingestion, was carried out in a previous study. The current study was performed to extend the analyzed conditions and confirm the results. The method to validate this technique is based on a comparison between hourly $F_{2}$ peak values measured with Vertical Incidence (VI) soundings and those calculated with the new technique. Data corresponding to different hours and seasons (equinox, summer solstice, and winter solstice) during the period 2000-2003 (high and medium solar activity conditions) were compared for all available ionosonde stations. The results show a good agreement between $f_{o} F_{2}$ and $h_{m} F_{2}$ values obtained with the new technique and measurements from vertical incidence soundings during quiet and storms conditions.
\end{abstract}

Key words electron density model - vertical incidence ionograms - ionospheric data ingestion

\section{Introduction}

One of the most unpredictable sources of error for single frequency satellite navigation and positioning systems is due to the ionosphere. A good knowledge of the behavior of the ionospheric regions is essential to obtain a better representation of parameters like the Total Electron Content (TEC) which is directly proportional to the time delay of electromagnetic signals.

A technique to reconstruct the spatial and temporal structure of the electron concentration in the ionosphere has been developed using the

Mailing address: Dr. Gloria Miró Amarante, The Abdus Salam International Centre for Theoretical Physics (ICTP), Strada Costiera 11, 34014 Trieste (Italy); e-mail: amarante@ictp.it
NeQuick ionospheric electron density model driven by an «effective ionization parameter» called Az (Nava et al., 2003). NeQuick is a quick-run model for ionospheric applications developed at The Abdus Salam ICTP in Trieste (Italy) and the University of Graz (Austria). It has been used by the European Space Agency ESA satellite navigation and positioning programs and adopted by Recommendation P.5316 of the ITU-R (International Telecommunication Union, Radiocommunication sector) (now superseded by P.531-7; ITU, 2001).

$A z$ values are determined minimizing the differences between experimental and modeled vertical TEC global maps. The result is a global grid of $A z$ values for a specific condition which allows us to calculate with the NeQuick model the electron density at any point in the ionosphere including the $F_{2}$ peak parameters values.

The aim of this paper is to compare these calculated $F_{2}$ peak values with independent and simultaneous global observations in order to validate the technique. These measurements, the criti- 
cal frequency in the $F_{2}$ region $\left(f_{o} F_{2}\right)$ and the height of the maximum of ionization $\left(h_{m} F_{2}\right)$, are obtained experimentally from ground-based vertical ionospheric sounders located around the world.

A preliminary validation was done (Miró Amarante et al., 2003) using data corresponding to four quiet days in the year 2002 (high solar activity conditions). The main results and conclusions of this analysis will be included in this paper.

\section{Ionospheric parameters measured with vertical incidence soundings}

The DIDbase software developed by Lowell University lets us extract ionograms from a network of digisondes distributed around the world. This possibility allows manual scaling of the available ionograms to measure the real values of the main ionospheric parameters (critical frequency, height, Ionospheric Total Electron Content - ITEC: Huang and Reinisch, 2001).

The analysis has been done for different conditions summarized in table I. For each period, all the available ionospheric stations were selected (fig. 1). The number of locations varies

Table I. List of selected periods for the validation of the reconstruction method.

\begin{tabular}{cccccc}
\hline \hline Day & Month & Year & $A p$ & Dst & $\begin{array}{c}\text { Sunspot } \\
\text { number }\end{array}$ \\
\hline 25 & 03 & 2000 & 8 & -9 & 185 \\
26 & 03 & 2000 & 3 & -1 & 170 \\
27 & 03 & 2000 & 4 & 1 & 155 \\
28 & 03 & 2000 & 4 & 1 & 169 \\
15 & 04 & 2002 & 6 & -8 & 138 \\
03 & 06 & 2002 & 10 & -21 & 133 \\
11 & 10 & 2002 & 6 & -38 & 121 \\
25 & 11 & 2002 & 15 & -46 & 56 \\
19 & 11 & 2003 & 12 & -179 & 70 \\
20 & 11 & 2003 & 150 & -152 & 90 \\
21 & 11 & 2003 & 42 & -76 & 97 \\
22 & 11 & 2003 & 30 & -63 & 83 \\
23 & 11 & 2003 & 22 & -38 & 109 \\
\hline
\end{tabular}

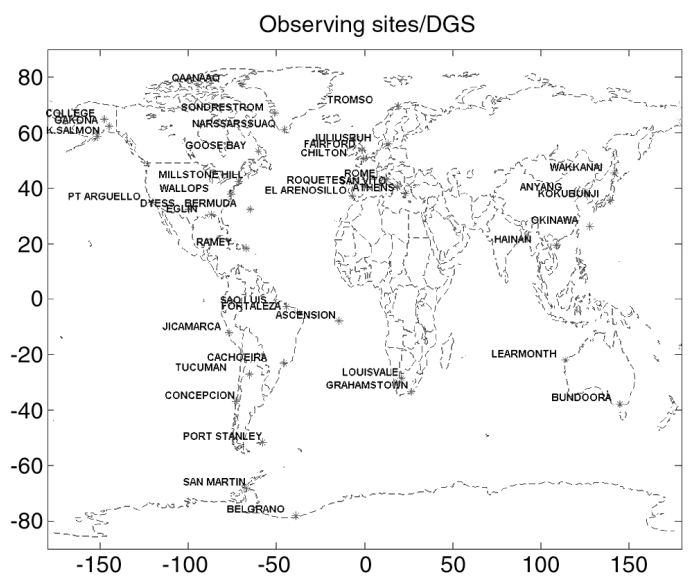

Fig. 1. Observing sites available for the periods analyzed.

from 13 during the period of March 2000 up to 27 for the 3rd of June 2002.

The manual scaling of the ionograms (almost 8300 ionograms) was done for each considered case and $f_{o} F_{2}$ and $h_{m} F_{2}$ were extracted to be compared with the reconstructed values.

\section{Ionospheric parameters calculated with the reconstruction technique}

Two global grids corresponding to $f_{o} F_{2}$ and $h_{m} F_{2}$ were obtained from the NeQuick model driven by the «effective ionization parameter» $A z$. This parameter is calculated by means of the technique described in Nava et al. (2003) in such a way that the differences between experimental and NeQuick model vertical TEC are minimum. The experimental vertical TEC maps used for the minimization are generated with two different techniques. The first is the one developed by CODE (Centre for Orbits DEterminations, http://www.cx.unibe.ch/aiub/ionosphere.html) with two hour intervals and the second one was generated by the University of La Plata, Argentina with one hour intervals (Meza et al., 2002; and Brunini et al., 2004).

The calculated $F_{2}$ peak values at the available digisonde locations (fig. 1) are extracted 
from these two global grids by interpolation since the $A z$ maps have a grid spacing of $2.5^{\circ}$ in latitude and $5^{\circ}$ in longitude.

\section{Comparison between measured and calculated peak values}

As an example, the critical frequency $f_{o} F_{2}$ and the maximum height $h_{m} F_{2}$ for Millstone Hill (middle latitude Northern Hemisphere) and Grahamstown (middle latitude Southern Hemisphere) are shown in fig. 2a-d (quiet period) and fig. 3a-d (storm period). Calculated $F_{2}$ peak values using CODE $\left(f_{o} F_{2} \mathrm{CODE}\right)$ and La Plata $\left(f_{o} F_{2}\right.$ LAPLATA) vertical TEC maps are plotted together with the experimental ones $\left(f_{o} F_{2} \mathrm{SAO}\right.$, obtained with Sao-Explorer, http://ulcar.uml.edu/ SAO-X/SAO-X.html).

The figures show a good agreement between both $f_{o} F_{2}$ data sets $\left(f_{o} F_{2} \mathrm{CODE}-f_{o} F_{2} \mathrm{SAO}\right.$ and $f_{o} F_{2}$ LAPLATA- $\left.f_{o} F_{2} \mathrm{SAO}\right)$ during quiet conditions while the differences between calculated and experimental values increase for geomagnetic disturbed conditions. The results are considerably worse in the case of $h_{m} F_{2}$. However, this is not surprising. NeQuick uses the CCIR (ITU-R) maps for $f_{o} F_{2}$ and $M(3000) F_{2}$ and an internal map for $f_{o} E$ to calculate $h_{m} F 2$ by means of Dudeney's form of the Bradley and Dudeney (1973) formula (see Dudeney, 1983) which works quite well for average (monthly median) conditions but can give larger errors in individual cases. Minimizing differences in electron content also means some minimization for $f_{o} F_{2}$ but $h_{m} F_{2}$ is not affected. The height error of true height analysis of ionograms can also be quite large.

The left panel of fig. 4 presents the scatter plot of $f_{o} F_{2}\left(F_{2}\right.$ peak electron density) reconstructed with the NeQuick model against the corresponding $f_{o} F_{2}$ ionosonde measurements for quiet periods (2000 and 2002). This example
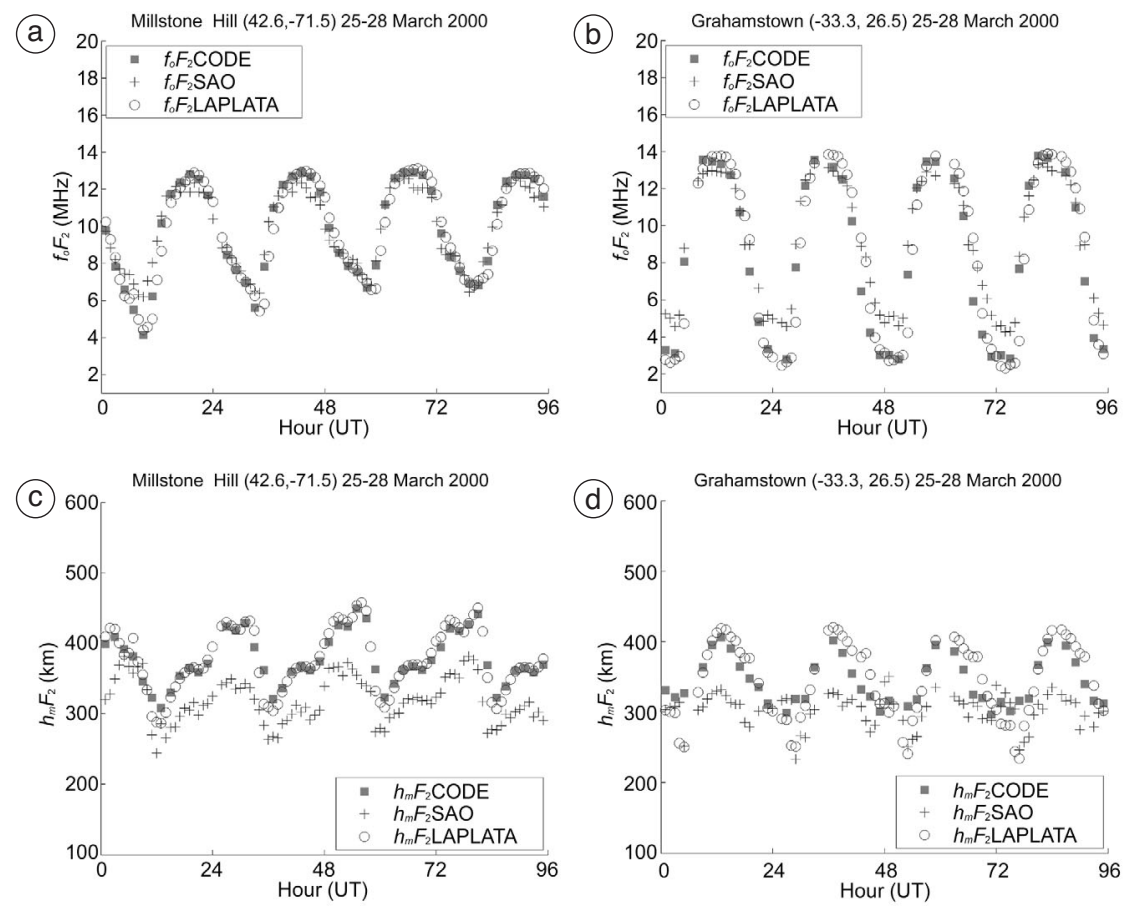

Fig. 2a-d. $f_{o} F_{2}$ (a) and $h_{m} F_{2}$ (c) for Millstone Hill (middle latitude Northern Hemisphere); $f_{o} F_{2}$ (b) and $h_{m} F_{2}$ (d) for Grahamstown (middle latitude Southern Hemisphere), during March 2000 (quiet period). 

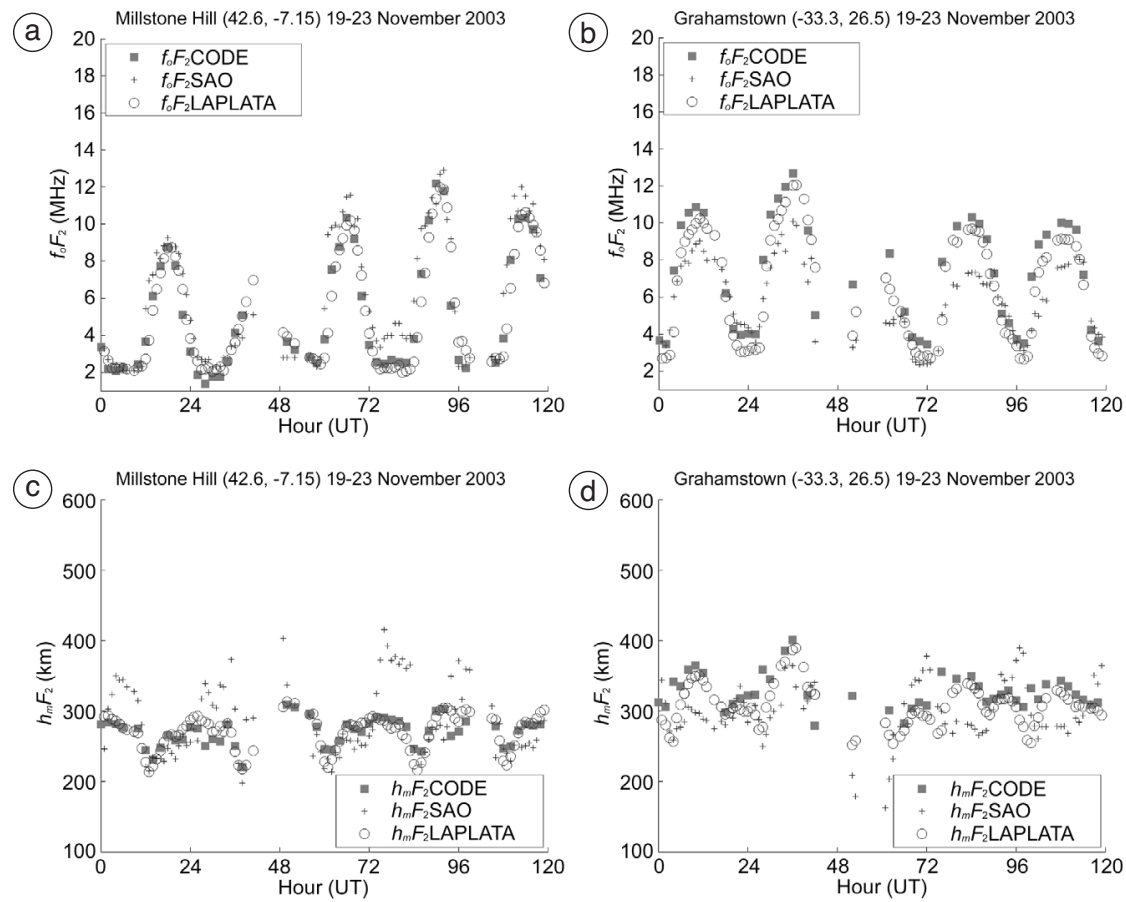

Fig. 3a-d. $f_{o} F_{2}$ (a) and $h_{m} F_{2}$ (c) for Millstone Hill (middle latitude Northern Hemisphere); $f_{o} F_{2}$ (b) and $h_{m} F_{2}(\mathrm{~d}$ ) for Grahamstown (middle latitude Southern Hemisphere), during November 2003 (storm period).
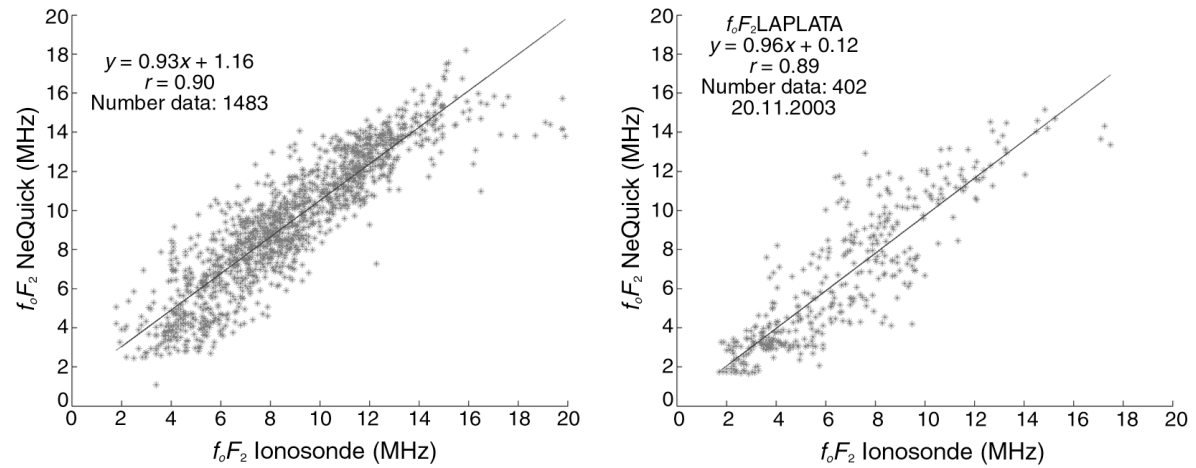

Fig. 4. Linear regression fitting for reconstructed and experimental $f_{o} F_{2}$ during quiet (left) and storm (right) conditions.

corresponds to CODE experimental vertical TEC maps. The scatter plot shows a high degree of correlation between the two independent estimates of $f_{o} F_{2}$. The line drawn corresponds to the best-fit line. Examination of the intercept of the best-fit line shows that on average the $f_{o} F_{2} \mathrm{NeQuick}$ values exceed those from digisondes by $\sim 1.16 \mathrm{MHz}$ during quiet period. The 
storm conditions are also shown on the right panel in fig. 4. This example corresponds to 20 th November $2003(A p$ index $=150)$ and shows how the agreement between both data sets is also obtained for a very disturbed day. It is important to point out that this storm occurred under middle solar activity conditions (sunspot number $=90$ ) and the analysis was done considering together all the ionospheric effects (positive and negative storms) distributed around the world.

The selected data are classified to create distributions with different conditions of solar activity, vertical TEC mapping technique and quiet or storm periods. The results of the linear regression fitting corresponding to each distribution are summarized in tables II and III for $f_{o} F_{2}$ and $h_{m} F_{2}$ respectively.
The correlation coefficients $R$ make clear the difference in accuracy for reconstruction of $f_{o} F_{2}$ and $h_{m} F_{2}$. In the case of the critical frequency the correlation coefficient is approximately 0.90 which means that the fitting between both data set is excellent. However this value does not exceed 0.70 for the peak height possibly for the reasons indicated above when discussing the results shown in figs. $2 \mathrm{a}-\mathrm{d}$ and $3 \mathrm{a}-\mathrm{d}$. The $f_{o} F_{2}$ reconstruction is also good during the studied storm period with values higher than 0.86 . It must be noted that regardless of the actual values of the correlation coefficient all the results indicate a very high statistical significance.

The comparison between the two vertical TEC mapping techniques (CODE and La Plata) does not show a clear dependence on the tech-

Table II. Linear regression fitting results for $f_{o} F_{2}\left(f_{o} F_{2} \mathrm{NeQuick}=A * f_{o} F_{2}\right.$ Ionosonde $+B ; R$ is the correlation coefficient and $N$ the number of selected data).

\begin{tabular}{|c|c|c|c|c|c|c|c|c|c|}
\hline \multicolumn{2}{|c|}{$f_{o} F_{2}(\mathrm{MHz})$} & \multicolumn{4}{|c|}{ La Plata } & \multicolumn{3}{|c|}{ CODE } & \multirow[b]{2}{*}{$N$} \\
\hline \multicolumn{2}{|c|}{ Period } & $A$ & $B$ & $R$ & $N$ & $A$ & $B$ & $R$ & \\
\hline \multirow{2}{*}{ Calm } & 2000 & 0.98 & 0.20 & 0.89 & 1096 & 1.01 & -0.10 & 0.91 & 547 \\
\hline & 2002 & \multicolumn{4}{|c|}{ No data } & 0.94 & 1.44 & 0.91 & 936 \\
\hline \multirow{5}{*}{ Storm period } & 19.11.2003 & 0.90 & -0.06 & 0.91 & 469 & 0.96 & -0.04 & 0.93 & 241 \\
\hline & 20.11 .2003 & 0.96 & 0.12 & 0.89 & 402 & 1.00 & 0.24 & 0.89 & 204 \\
\hline & 21.11 .2003 & 0.76 & 0.74 & 0.86 & 379 & 0.79 & 0.98 & 0.87 & 181 \\
\hline & 22.11 .2003 & 0.91 & 0.17 & 0.88 & 463 & 0.96 & 0.23 & 0.89 & 232 \\
\hline & 23.11 .2003 & 0.86 & 0.48 & 0.89 & 457 & 0.92 & 0.53 & 0.90 & 225 \\
\hline
\end{tabular}

Table III. Linear regression fitting results for $h_{m} F_{2}\left(h_{m} F_{2}\right.$ NeQuick $=A * h_{m} F_{2}$ Ionosonde $+B ; R$ is the correlation coefficient and $N$ the number of selected data).

\begin{tabular}{|c|c|c|c|c|c|c|c|c|c|}
\hline \multirow{2}{*}{\multicolumn{2}{|c|}{$\begin{array}{c}h_{m} F_{2}(\mathrm{~km}) \\
\text { Period }\end{array}$}} & \multicolumn{4}{|c|}{ La Plata } & \multicolumn{4}{|c|}{ CODE } \\
\hline & & \multirow{3}{*}{$\begin{array}{c}A \\
0.34\end{array}$} & \multirow{2}{*}{$\begin{array}{c}B \\
187.7\end{array}$} & \multirow{2}{*}{$\begin{array}{c}R \\
0.53\end{array}$} & \multirow{2}{*}{$\frac{N}{1094}$} & \multirow{2}{*}{$\frac{A}{0.35}$} & \multirow{2}{*}{$\frac{B}{183.9}$} & \multirow{2}{*}{$\begin{array}{c}R \\
0.48\end{array}$} & \multirow{2}{*}{$\frac{N}{546}$} \\
\hline Colm & 2000 & & & & & & & & \\
\hline CantI & 2002 & & \multicolumn{3}{|c|}{ No data } & 0.55 & 128.6 & 0.60 & 529 \\
\hline \multirow{5}{*}{ Storm period } & 19.11 .2003 & 0.75 & 70.0 & 0.70 & 325 & 0.72 & 72.5 & 0.68 & 165 \\
\hline & 20.11 .2003 & 0.62 & 129.4 & 0.50 & 279 & 0.56 & 141.9 & 0.46 & 140 \\
\hline & 21.11.2003 & 0.72 & 90.1 & 0.50 & 242 & 0.80 & 68.2 & 0.52 & 113 \\
\hline & 22.11 .2003 & 0.76 & 80.1 & 0.66 & 324 & 0.72 & 83.1 & 0.67 & 164 \\
\hline & 23.11 .2003 & 0.72 & 90.2 & 0.68 & 323 & 0.62 & 113.3 & 0.66 & 156 \\
\hline
\end{tabular}


nique of the vertical TEC map used to derive $A z$ values. The number of points corresponding to La Plata technique is higher because these maps are obtained hourly.

The dependence on solar activity is only noticeable for $h_{m} F_{2}$ where the fitting improves when solar activity decreases. However, further analysis considering low solar activity and storm conditions under very high solar activity should be done in the future.

\section{Conclusions}

The comparison of $F_{2}$ peak values generated by the new technique of $3 \mathrm{D}$ reconstruction of the electron density and the corresponding vertical incidence ionosonde data covering a wide area of different geographical, seasonal and hourly conditions indicates that:

- The critical frequency of the $F_{2}$ layer shows a very good agreement between both data sets during high and middle solar activity quiet periods.

- This agreement is also good for the November 2003 storm considering together all the ionospheric effects (positive and negative storm effects) distributed around the world.

- The $h_{m} F_{2}$ parameter shows a worse agreement than $f_{o} F_{2}$ values and the worst results have been found for high solar activity.

- The results obtained are not dependent on the technique of the vertical TEC maps used, CODE and La Plata.

Therefore, it has been demonstrated that the new technique can be used to build scenarios that reproduce global ionospheric conditions in a realistic way.

\section{Acknowledgements}

The Aeronomy and Radiopropagation Laboratory group of The Abdus Salam International Centre for Theoretical Physics is grateful to the University of La Plata for providing their vertical TEC maps and to the ionospheric groups (Lowell University (U.S.A.), National Observatory of Athens (Greece), Radio Research Labo- ratory (Sinpil Seolsung Ichon Kyunggi, Republic of Korea), Rhodes University (Grahamstown, South Africa), Communications Research Laboratory (Tokyo, Japan), Rutherford Appleton Laboratory (Chilton, United Kingdom), Istituto Nazionale di Geofisica e Vulcanologia (Rome, Italy), INTA (Huelva, Spain), Ebro Observatory (Spain), CASLEO (San Juan, Argentina)) from whom we received data used in this study. One of the authors (G.M.A.) also wants to thank to the Marie Curie Fellowship of the European Community Fifth Framework Programme under contract No. HPMF-CI-2002-01867 for supporting this research.

\section{REFERENCES}

Bradley, P.A. and J.R. Dudeney (1973): A simple model of the vertical distribution of electron concentration in the ionosphere, J. Atmos. Terr. Phys., 35, 2131-2146.

Brunini, C., A. Meza, F. Azpilicueta, A. Van Zele, M. GENDE and A. DiAZ (2004): A new ionosphere monitoring technology based on GPS, Astrophys. Space Sci., 290 (3), 415-429.

DuDENEY, J.R. (1983): The accuracy of simple methods for determining the height of the maximum electron concentration of the $F_{2}$-layer from scaled ionospheric characteristics, J. Atmos. Terr. Phys., 45, 629-640.

HuANG, X. and B.W. Reinisch (2001): Vertical electron content from ionograms in real time, Radio Sci., 36 (2), 335-342.

ITU (2001): Ionospheric propagation data and prediction methods required for the design of satellite services and systems ionosphere characteristics, Recommendation P.531-6, approved in 2001-02, managed by ITU-R Study Group SG3 (version 6 superseded in 2004 by version 7).

Meza, A., C.A. Brunini and A. KLAeusberg (2002): Global behaviour of the ionosphere electron density using GPS observations, Adv. Space Res., 30 (2), 307-312.

Miró Amarante, G., S.M. Radicella, B. Nava and P. CoÏsson (2003): Validation of a new method for ionospheric electron density reconstruction by means of vertical incidence data, in Proceedings of 'Atmospheric Remote Sensing using Satellite navigation Systems', Special Symposium of the URSI Joint Working Group, Matera (FG), Italy, 335-342.

Nava, B., P. CoÏsson, G. Miró Amarante and S.M. RadiCELLA (2003): A new model assisted method for ionosphere electron density reconstruction, in Proceedings of 'Atmospheric Remote Sensing using Satellite navigation Systems', Special Symposium of the URSI Joint Working Group, Matera (FG), Italy, 343-348.

(received October 18, 2004 accepted March 19, 2005) 